\title{
Course Management For Novice It Professionals
}

\author{
Chieko Hashimoto and Yoichi Murakami
}

Institute of Advanced Business System, Hitachi Ltd.,2-2

Kagahara,Tuzuki-ku,Yokohama,224,Japan, 81-45-948-1415, 81-45-948-1419, chie@iabs.hitachi.co.jp,mura@iabs.hitachi.co.jp

\section{Tsurayuki Kado}

Information Systems Group, Hitachi Ltd., 27-18 Minami Oi 6-chome,Shinagawa-ku,Tokyo,140, Japan

81-3-5471-8960,81-3-5471-2564

t-kado@comp.hitachi.co.jp

\begin{abstract}
An intellectual occupation of a consultant who is required to solve various business problems depends greatly on an individual's ability. A very high priority in the organisation is to be a skilful judge of talent and to cultivate the abilities and individuality of its selected recruits. The authors address these difficult problems and offer their results.

This paper describes the planning strategy to develop its new recruits, a course management, the correspondence to IT Professionals definition by MITI, and the project exercise concerning the entry-level engineer's training.
\end{abstract}

\section{Keywords}

Bringing-up Talent, Technology Discipline, Technical Level Protocol, Carrier Pass for Qualification, Entry-Level Training

\section{INTRODUCTION}

The Institute of Advanced Business Systems $I A B S$ was separated from the Information Systems Division in 1990 to specialise in Strategic Information Systems SIS which was booming in Japan during the latter half of the 1980's. At that time, the DOMINO storm grew in intensity. DOMINO is an acronym for Down-sizing, Open, Multi-media, Inter-operability, 
Network and Object-oriented. During this period of innovation, business system and problem solving analysis grew in demand within the consulting industry. The main business in IABS is the consultation of upstream processes. Consequently, the personnel are required to not only have the information technology skills, but also general skills such as negotiating and presenting. A very high priority in $I A B S$ is to recruit, develop, and keep newly recruited employees. Top management emphasise that an essential part of the management education is the course planning based on an individual's necessary technical skills and knowledge. To be more effective, the entry-level training program must be expanded. All students must acquire essential skills as well-rounded individuals and select every course. The authors challenged students to explore their potential. To be concrete, we improved the traditional one-way lecture style and introduced the synthetic exercise using the Teach Each Other Learning System. As a result, all students were convinced of their preliminary assignment and were attached joyfully to their respective departments.

\section{PLANNING STRATEGY AND COURSE MANAGEMENT}

\subsection{The course setting objectives}

As members of Business System Creator BSC, new recruits are expected to acquire the following technical skills and knowledge. 1. expert knowledge such as information technology, business applications, thinking faculty and problem solving techniques

2. consultation, presentation and negotiation skills for dispatch of new technology.

$B S C$ must promote the development of the concept using innovative planning techniques and leading-edge information technology. $B S C$ must contribute to the enterprise by quickly developing concept.

The skill development method goes through the following four steps. First, to demonstrate clearly the business strategy. Secondly, to decide the qualifications and tasks. The third step is to prepare the technology discipline and the technical level protocol. The final step is the execution of the plan. All personnel are separated into three ranks: high $H$, medium $M$ and low $L$. The discipline which defines the technology acquired by the personnel is named the technical level protocol.

Figure 1 shows a course setting and the personnel classification. The course consists of three core parts: consulting $C$, research and development $R$ and marketing $M$. Furthermore, the courses $\mathrm{C}$ and $\mathrm{R}$ separate the business and information technology fields respectively. All personnel belong to every part assigned to rank $H$ and $M$, but there is no parts in rank $L$. Personnel in rank $\mathrm{L}$ can select every part after they are promoted to rank $\mathrm{M}$. This is our design philosophy. Training for entry-level begins at an introductory level to rank $\mathrm{L}$. All personnel can select another part when promoted to the next rank. This design philosophy is based on our management policy that An equal chance for an individual to grow the organisation. 


\begin{tabular}{|c|c|c|c|c|c|}
\hline \multirow{2}{*}{$\begin{array}{c}\text { Class } \\
\text { Rank }\end{array}$} & \multicolumn{2}{|c|}{$C$} & \multicolumn{2}{c|}{$R$} & \multirow{2}{*}{$M$} \\
\cline { 2 - 5 } & Business & $I T$ & Business & $I T$ & \\
\hline$H$ & $\mathrm{CAE}, \mathrm{CBI}$ & $\mathrm{CC1}$ & $\mathrm{RA} 1, \mathrm{RB} 1$ & $\mathrm{RC1}$ & $\mathrm{MA1}, \mathrm{MB} 1$ \\
\hline$M$ & $\mathrm{CA} 2, \mathrm{CB} 2$ & $\mathrm{CC} 2$ & $\mathrm{RA} 2, \mathrm{RB} 2$ & $\mathrm{RC} 2$ & $\mathrm{SE}$ \\
\hline$L$ & \multicolumn{4}{c|}{$\mathrm{SS}$} \\
\hline \multicolumn{5}{c|}{ Training course for entry-level } \\
\hline
\end{tabular}

Figure1 Course setting and classification

SE:Sales Engineer

\subsection{The technology discipline and the technical level protocol}

The technology discipline, shown in Figure 1, defines the items of technology required by all personnel. The vertical region in this figure separates the expert knowledge, process-oriented technology, and common technology. Business and industry knowledge, as well as the knowledge for hardware/software/system in an information technology field come under the expert knowledge respectively. The planning methodologies in a business field and the system development method in an IT field come under the process-oriented field. Presentation, communication, and problem-discovering/solving skills in the common technologies also come under the expert knowledge.

The technical level protocol provides knowledge and a level of technology defined by the discipline.

\subsection{The correspondence to the IT professionals}

The Ministry of International Trade and Industry MITI defines an information-oriented individuals with advanced expertise and experience as IT Professionals. The IABS business is greatly influenced by many public qualification standards such as MITI's. Figure 2 shows the similarities in training received by an IABS personnel and a IT professional in ITEE. Although they are not exactly the same, there are many overlapping areas. So, $I A B S$ recommends that all personnel acquire the necessary public qualifications.

\begin{tabular}{|c|c|c|c|c|c|c|c|c|}
\hline \multirow{3}{*}{$\begin{array}{l}\text { Course } \\
\text { in IABS }\end{array}$} & \multicolumn{3}{|c|}{$\mathrm{C}$} & \multicolumn{3}{|c|}{$\mathbf{R}$} & \multirow{2}{*}{\multicolumn{2}{|c|}{$\mathbf{M}$}} \\
\hline & \multicolumn{2}{|c|}{ Business } & IT & \multicolumn{2}{|c|}{ Business } & \multirow{2}{*}{$\begin{array}{c}\mathrm{IT} \\
\mathrm{RCl}\end{array}$} & & \\
\hline & CAl & CB1 & $\mathrm{CCl}$ & RAl & RBI & & MAl & MB1 \\
\hline $\begin{array}{c}\text { IT } \\
\text { Professionals } \\
\text { in ITEE }\end{array}$ & & & $\begin{array}{l}\mathrm{AE}, \\
\mathrm{TS}\end{array}$ & & & $\begin{array}{l}\mathrm{AE}, \\
\mathrm{TS}\end{array}$ & & AN, \\
\hline
\end{tabular}

AE:Application Systems Design Engineer, SAN:Systems Analyst, TS:Technical Specialist

Figure 2 Correspondence to IT professionals 
The Information Technology Engineer Examination ITEE promoted by MITI is quite similar to the Accreditation Board for Engineering and Technology ABET. Presently, ITEE is not a mandatory qualification like $A B E T$, but only a desirable objective. The main reason is due to the Permanent Employment System. Since this concept is easily misunderstood, it is better to use the expression, "Longtime Employment System." Although this traditional labor system began to disintegrate after the oil crisis, the Japanese culture is still deep-rooted. The idea that the enterprise is obliged to develop its talent has a national consensus, so the argument about a vocational education in Japan must be set this thought forth as a major premise. However, many Japanese software firms which can not provide an education and training department impose conditions on the public qualification.

\subsection{A mechanism of the course management}

Figure 3 shows a mechanism of the course management to promote skill-building of its personnel. As the first step, the personnel and the manager confirm an employee's current position and rank based on one's technical level protocol. In the second step, they decide the future target and design plans in order to acquire the necessary technical skills and education. At the same time, they select one of the following methods: OJT, Off-JT and Self Development. Then, they set goals for the appropriate public qualifications. The third step is the execution. Repeating this process every six months produces the precise course management.

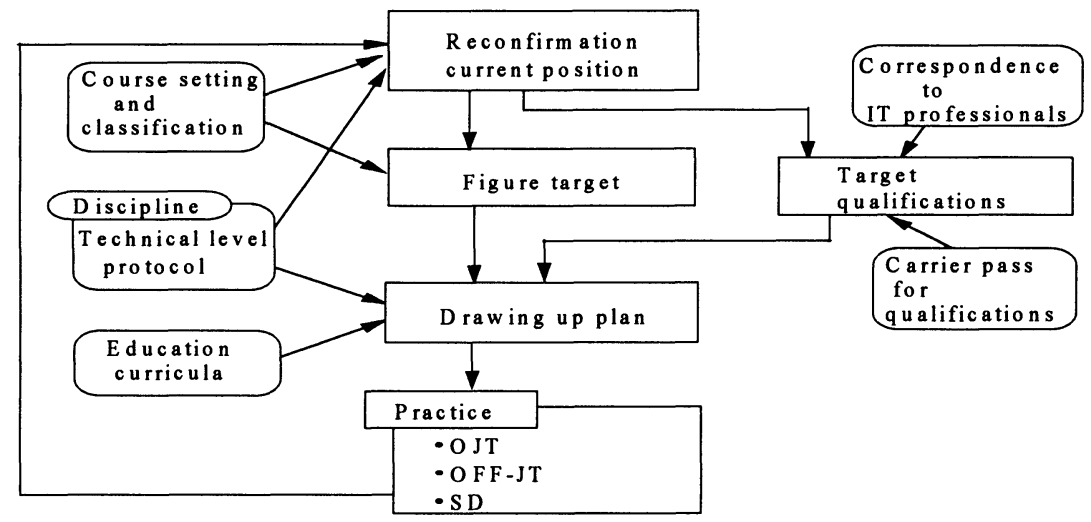

Figure 3 Mechanism of course management

\subsection{The entry-level training}

\section{Outline of curriculum}

This curriculum is based on the necessary abilities and skills described in section 2.2. The curriculum is composed of three steps. Figure 4 shows an outline of the curriculum. The aim of this curriculum can be found in step 3. Step 1 and 2 are only a preparation to accomplish step 3. All of the system development process, mainly system analysis of the testing are to be experienced in step 3 . This is executed in each group. 


\begin{tabular}{|c|l|l|}
\hline step & \multicolumn{1}{|c|}{ unit / form } & \multicolumn{1}{|c|}{ contents } \\
\hline 1 & Basic grammar of C language / & Input-calculation-output, real number data, control \\
$(66 \mathrm{H})$ & Individual exercises & structure, array, function, and file processing \\
\hline 2 & $\begin{array}{l}\text { Small system constructing exercises } \\
\text { from the downstream processes / } \\
\text { Individual exercises }\end{array}$ & $\begin{array}{l}\text { Reuse of program compositions expansion of program } \\
\text { specification and correspondence to program specification } \\
\text { change }\end{array}$ \\
\hline 3 & $\begin{array}{l}\text { System development exercises from } \\
\text { the upstream processes / } \\
(68 \mathrm{H})\end{array}$ & $\begin{array}{l}\text { System analysis, system planning, system design, program } \\
\text { design, programming and testing }\end{array}$ \\
\hline
\end{tabular}

Figure 4 Outline of the curriculum

These are distinct differences compared to the traditional education method. The old curriculum emphasised programming exercises performed by the individual. Additionally, this curriculum includes not only the system construction ability but also the human skills. Writing, presentation and problem finding/solving abilities are developed specifically in the curriculum.

\section{Execution result}

The curriculum was implemented by 14 employees in 1994. The following includes students' reactions to the curriculum and the curriculum's outcome on system construction. ability and human skill.

(1)System construction ability

Pre-test and post-test concerning the program's effectiveness were taken to measure the effect of the curriculum. The two tests included the same format and were of the same difficulty. Figure5 shows the test results. All participating students were able to achieve their target. Especially, two students who did not have the programming experience showed the greatest advancement. Moreover, the necessity and work procedure of each system development process were better understood after the exercises.

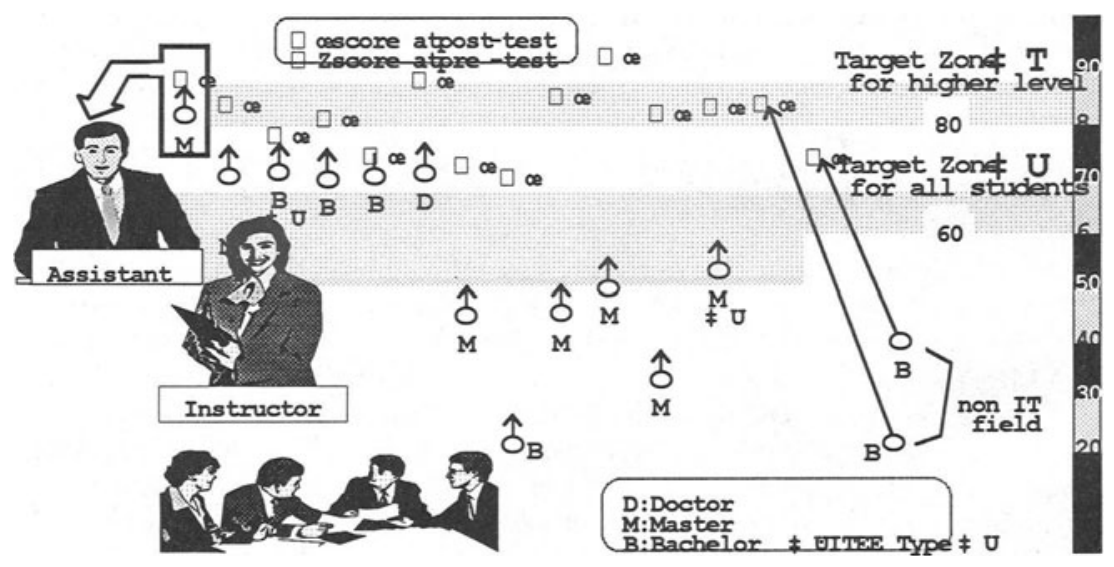

Figure 5 Aims of the Curriculum and results 
The completed systems strongly showed originality which was a selling point of the group" according to each group. The students enjoyed original work during products-making". However, it was not always fun. The students sometimes worried when the program which they designed did not work. Thus,both pleasure and pain were experienced during system development.

(2)Human skill

The system analysis might have been a fresh experience for the students, since they are usually accustomed to programming the set problem. It was possible to make the student generally understand the purpose and procedure of the system analysis. This approach will be useful as an introduction as a variety of analysis techniques will be learned in the future.

Whenever a presentation was repeated, improvements were evident in the content of the announcement, material, and the attitude. On the other hand, problems remained in the writing ability area. Most students wrote the document unskilfully at first. Many poor documents were submitted by the students. First of all, it was necessary to change the consideration of the students to the document. Then, design specification was shared in the group and the lecturer corrected documents submitted. As a result, the purpose of the document was understandable. That is, the students recognised that it was necessary to write sentences which a stranger would be able to understand. However, large improvements were not seen in writing ability. In addition to this curriculum, a course on penmanship is necessary.

Mature growth of cooperation, leadership, and sense of responsibility, etc. were seen of the students through the group exercise. Additionally, having completed one system will increase confidence to do business in the future. On the other hand, there were reflections. For instance, in the group, work is not evenly distributed and communication channels were not clear. It is not because everyone succeeds by joint work. These reflections should be useful for business in the future. It is difficult to emphasise the importance of communication and leadership understood by the explanation. It was clear that learning by experience was the best means.

\section{CONCLUSION}

The authors attained most of the above objects during a three month period Off-JT. The students became familiar with the Hitachi culture and understood our development plan for talent in $I A B S$. This training course gained a position as an introduction to $I A B S$. In addition to technical growth, cooperation, leadership, mental growth as patience is involved in program perfection achieved recognition in recent months. This synthetic exercise is in a primary version of the popular Software Hut Education in the Software Engineering Project Program $S E P$, which is held for more experienced system engineers at the Hitachi Institute of Technology HIT.

The success of intellectual employment as a software production depends on management. The term management which originally means a suitable treatment for age, experience and ability has come to mean a shrewd judge of talent who cultivates their abilities and individuality. The character kan-ri is usually translated as administration, management, control, supervision and superintendence et al. On the contrary, the Chinese kanji character for kan-ri originally means to supervise to not go beyond the limit or fence. Therefore, almost all Japanese leaders consequently apt to interpret unconsciously to control with regulations because of its etymology and nuance. It stands to reason that a stereotyped education is found in some places in Japan. It goes without saying that this is an undesirable phenomenon.

Software production depends on individual abilities. The managers concerned must 
emphasise not only group development, but also individual's development. The strength of the chain is decided by the strength of its weakest link.

\section{ACKNOWLEDGMENTS}

The author's would like to express acknowledgment to Prof. Hajime Ohiwa (Keio Univ.), who has directly undertaken guidance. Thanks also to Mr.Kazuo Okazaki(Hitachi Medical Corp.) and Mr. Ryosaku Motoda (Hitachi Ltd.) for giving us to the opportunity to do these important experiments. Thanks also to Mr. Binzee R. Gonzalvo (Hitachi ,Ltd.), Ms. Mayumi Yano, Ms. Natsuko Nomaguchi and Ms. Katsuko Kishida (Hitachi Information Academy Ltd.) for their help in the editing of this paper.

\section{REFERENCES}

N. Takeda et al., A Curriculum for Developing Software Engineers' Discipline through Program Development Experiences, 1992

C. Hashimoto, Development and Implementation of Systems Engineer Curriculum for Upstream Activities through Program Development Experience,1996

Y. Murakami, Employee Education, 1994

T. Kado et al., Software Hut Education in Hitachi,AEESEAP96,1996

\section{BIOGRAPHY}

Chieko HASHIMOTO: instructor,

Education \& Training 5 years

Yoichi MURAKAMI: Senior Engineer

Hardware Design 18 years, CASE 3 years, Education \& Training 2 years

Tsurayuki KADO: Chief Instructor,

Hardware Design 2 years, Software Design 8 years, Systems Engineering 12 years,

Education \& Training 10 years 